\title{
WSPOMNIENIE O PROFESORZE GINTERZE TRYBUSIU
}

\author{
Ginter Trybuś umarł w USA przy komputerze
}

Ginter Trybuś urodził się 13 czerwca 1940 roku w Rybniku. Zmarł 6 lutego 2014 roku w Chatsworth w Kalifornii. Ginter żył komputerem i zmarł przy komputerze.

W latach 1959-1964 studiował matematykę na Uniwersytecie Wrocławskim. Pracę magisterską Rozwiązywanie równań wyktadniczych przygotował $\mathrm{w}$ Katedrze Metod Numerycznych pod kierunkiem profesora Stefana Paszkowskiego. Studia ukończył z

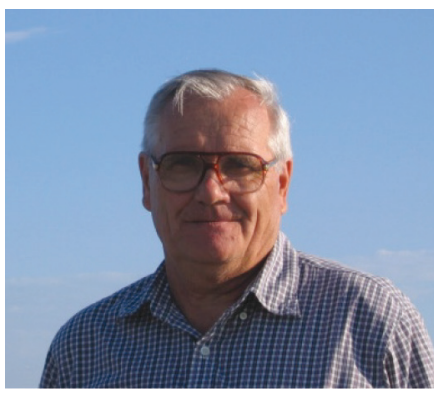
wynikiem bardzo dobrym. W 1963 roku poślubił Elżbietę Trybusiewicz, koleżankę z roku; miał z nią troje dzieci: Iwonę, Annę i Krzysztofa. W dniu narodzin syna powiedział, że troska o dzieci jest dla niego jedynym celem życia. Pracę w Wyższej Szkole Ekonomicznej we Wrocławiu rozpoczął najpierw w Katedrze Matematyki, a w rok później - w odpowiedzi na propozycję profesora Hellwiga - przeszedł do Katedry Statystyki, gdzie pracował - na różnych stanowiskach - aż do chwili opuszczenia Polski i wyjazdu do Stanów Zjednoczonych w 1982 roku. Pracę doktorską Numeryczne aspekty wyznaczania dystansów napisał pod kierunkiem profesora Zdzisława Hellwiga. Obronił ją w 1970 roku na Wydziale Gospodarki Narodowej Wyższej Szkoły Ekonomicznej. Jednym z recenzentów tej dysertacji był profesor Bolesław Kopociński - wybitny znawca tej problematyki. Po obronie Ginter Trybuś został awansowany na stanowisko adiunkta. Nauczał przedmiotów z takich dziedzin, jak: metody numeryczne, programowanie komputerów (zwanych wtedy elektronicznymi maszynami cyfrowymi), języki algorytmiczne, statystyka i ekonometria. Opiekował się również pracami magisterskimi. Był lubiany przez studentów za prowadzone na wysokim poziomie i zrozumiałe zajęcia dydaktyczne oraz swoisty humor.

Jego ojciec w czasie drugiej wojny światowej, jako Ślązak, był wcielony do Wehrmachtu i walczył pod Stalingradem, gdzie - bez głębszych studiów statystycznych - poznał istotę zjawisk masowych: Nec Hercules contra plures. Prawo stabilności szeregów statystycznych Lexisa obowiązuje wszędzie - nawet na froncie w warunkach ostrej zimy. Wilhelm Lexis był także - jak Ginter - w swoim czasie profesorem we Wrocławiu. 


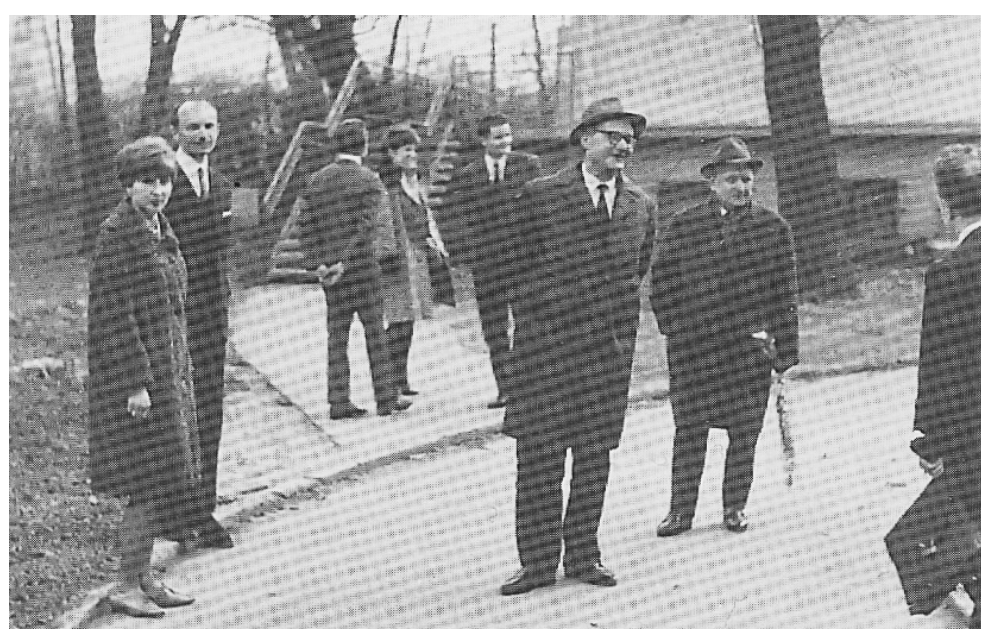

Kampus Uniwersytetu Ekonomicznego we Wrocławiu.

Przerwa w obradach Konferencji Polski Południowej, 1967.

Od prawej: W. Bukietyński (tyłem), K. Zając, Z. Pawłowski, G. Trybuś, U. Królik (później Siedlecka), C. Szmigiel (tyłem), A. Smoluk, N.N.

Z Leningradu - był tam pół roku na stażu naukowym - oprócz zdobytego doświadczenia naukowego przywiózł wiele anegdot. Jego ulubioną przypowieścią, powtarzaną przy różnych okazjach, jest szmonces o lwach. W czasie Wielkiej Wojny Ojczyźnianej oficer podrywa sołdatów do ataku. - Orly w pieriod! Batalion wyskakuje z transze jak na skrzydłach, ale dwóch żołnierzy siedzi spokojnie w okopie. Nu, a wy szto? - A my nie orly, my lwy: Lew Abramowicz i Lew Isakijewicz. Naturalnie ta anegdota nie ma nic wspólnego z rasizmem, a tym bardziej z antysemityzmem, albowiem Żyd to obrzezany Polak, a Polak to ochrzczony Żyd. Druga anegdota jest równie piękna. Na balu kilku młodzieńców nie tańczy, lecz podpiera ścianę. Pada pytanie: dlaczego nie tańczycie? - a, bo my nie tańcjory, my połowych diet mastiera. Piękny rosyjski kalambur - autorstwa mało znanego rosyjskiego poety, Koli Łancowa, który mawiał o sobie z dumą: ja połowych diet mastier - jest eufemizmem zastępującym jedno niecenzuralne słowo Gintera. Dla nierusycystów przypominamy, że słowo poł może znaczyć zarówno podłogę, jak i płeć. Sam Łancow miał burzliwą i ciekawą przeszłość związaną z Polską. Wyszkolono go na szpiega mającego śledzić armię Andersa. Języka polskiego uczyła go najprawdziwsza polska hrabina Telimena z czasów drugiej wojny światowej.

Wzorcem mężczyzny, według Gintera, jest ktoś mający żonę, trójkę dzieci, kochankę, dom i samochód. Nie oznacza to jednak, że Ginter był prawdziwym mężczyzną według własnej definicji.

Był koleżeński, życzliwy i pomocny. W stanie wojennym sklepy były puste, a towarów nie kupowano, lecz je zdobywano. Któryś z jego kolegów poskarżył się na brak pasty do zębów. Ginter natychmiast, jak spod ziemi, wyciągnął tubkę i wręczył mu ją, naturalnie bez żadnej rekompensaty. 


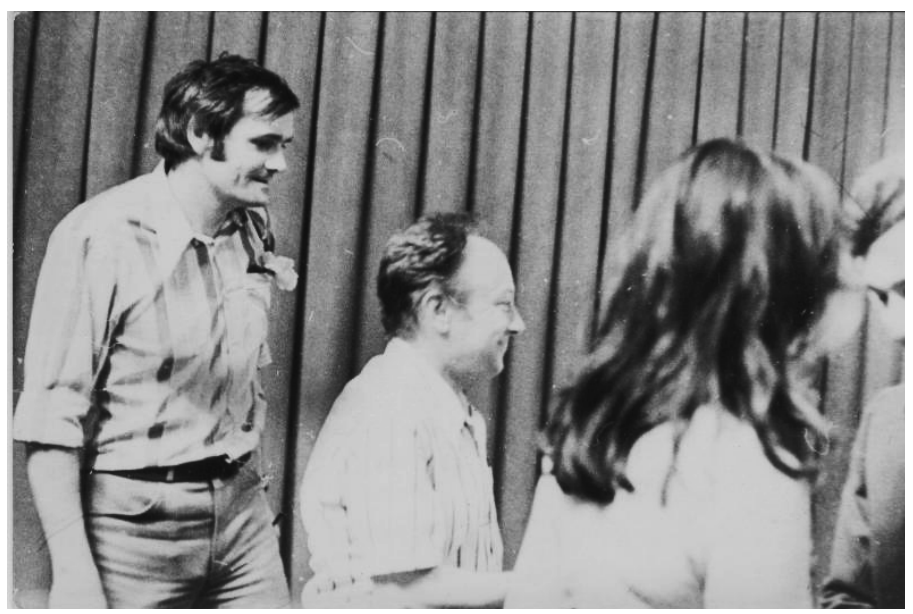

G. Trybuś, W. Bukietyński i N.N.

Powoływano go często na opiekuna grupy studenckiej. Rektor Józef Popkiewicz, na wniosek dyrektora instytutu, zaliczył go w 1977 roku do grupy przodujących nauczycieli uczelni; to zaszczytne miano otrzymywał jeszcze kilkakrotnie. W tym samym roku odznaczono go srebrnym krzyżem zasługi. W tym czasie rektor powołał go na kierownika punktu konsultacyjnego w Dzierżoniowie. Do pracy jeździł tam razem z profesorem Władysławem Bukietyńskim. Z luźnych uwag ich obu można wnosić, że:

\section{panny to ma stodziutkie, ten gród, jak sok, czekolada i miód.}

Naturalnie mowa tu o tym dolnośląskim mieście, a nie o Lwowie. Można im było tylko zazdrościć tych wyjazdów. Ale czy byłaby to tylko zwykła zawodowa jalousie de métier? Obaj, Ginter i Unek, byli mężczyznami na 102\%, chociaż nie zajmowali się cyklinowaniem parkietu.

Habilitował się w roku 1982 na Wydziale Zarządzania i Informatyki. Przygotował książkę Zmienna losowa dystansowa. Teoria i zastosowania, która traktuje o ciekawym problemie związanym z badaniem rozkładów statystyk ekstremalnych. Problem ten badali tacy znani wrocławscy matematycy, jak Stefan Zubrzycki, Bolesław Kopociński i inni. Tematyka ta dotyczy badania próby losowej. W rosnącym ciągu prób losowych można związać kilka ważnych zmiennych losowych - procesów stochastycznych. W tym kręgu tematycznym mieści się szukanie rozkładu wartości maksymalnej, minimalnej i średniej w próbie, a także rozkładu dystansów. Rozkład dystansów jest użytecznym narzędziem w badaniu problemu komiwojażera oraz w zadaniach taksonomicznych. W kręgu tej problematyki znajduje się tak zwany ciąg Ulama, uogólniający deterministyczny ciąg Fibonacciego. Fibonacci opisuje rozród królików, natomiast Ulam próbuje modelować reakcję łańcuchową. Pojęcie 
ciągu Ulama jest użyteczne w fizyce atomowej, a ostatnio próbuje się stosować go również $\mathrm{w}$ badaniach nad zachowaniem się giełdy. Niech $a_{0}=0, a_{1}=1$, oraz $a_{n+2}=a_{n+1}+b_{n}$, gdzie $b_{n}$ jest zmienną losową przyjmującą z równym prawdopodobieństwem wartości $a_{k}$ dla $k \in\{0, \ldots, n\}$.

Doktor Trybuś okazał się płodnym badaczem rozkładów ekstremalnych; on właśnie wskazał nowe obszary zastosowań zmiennych losowych dystansowych. Problematyka ta jest aktualna. Metodami zaproponowanymi przez niego można w sposób przybliżony rozwiązywać różnorakie problemy praktyczne, poczynając od wyboru najkrótszej drogi w klasycznym problemie komiwojażera, a kończąc na zadaniach klasyfikacyjnych taksonomii i paleontologii. Praca ta w roku 1983 została nagrodzona przez Główny Urząd Statystyczny. Jej autor był również wielokrotnie nagradzany przez rektora za osiągnięcia naukowe, dydaktyczne i administracyjne. Znany jest jego oryginalny i piękny algorytm wyznaczania generatorów wypukłej otoczki punktów ekstremalnych: skończonego zbioru punktów leżących na płaszczyźnie.

Od 1971 roku sprawował funkcję kierownika naukowego w ośrodku obliczeniowym. W roku akademickim 1970/1971 przebywał w Leningradzie na stażu naukowym. Po habilitacji został mianowany docentem w Instytucie Cybernetyki Ekonomicznej Akademii Ekonomicznej we Wrocławiu, którego to w latach 1981-1984 był wicedyrektorem. Obok badań teoretycznych prowadził prace na rzecz gospodarki narodowej; interesował się wykorzystaniem programowania liniowego w planowaniu produkcji, zagadnieniem transportowym oraz sekwencyjnymi metodami weryfikacji hipotez statystycznych. Wizytował Uniwersytet w Marburgu oraz Wyższą

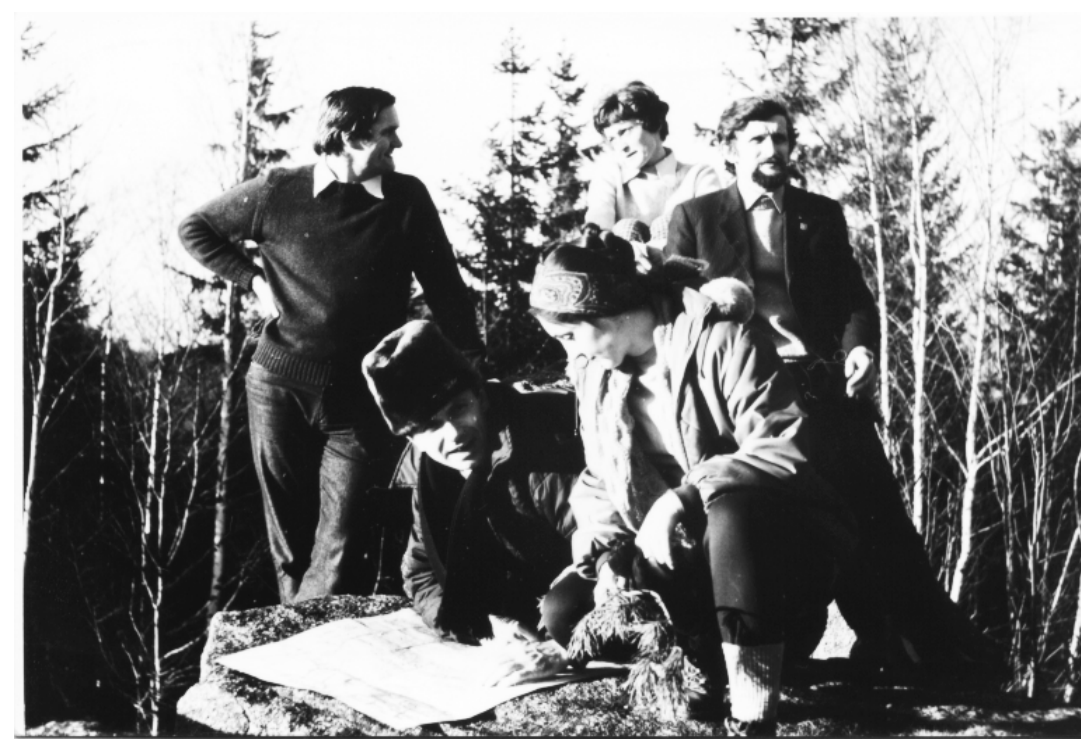

Weekend w Zachełmiu, 1979 rok

Od lewej: G. Trybuś, A. Smoluk, E. Stolarska (AE Katowice), M. Cieślak, S. Krawczyk 
Szkołę Ekonomiczną w Pradze. Znał biegle 5 języków: polski, niemiecki, rosyjski, czeski i angielski. Po wyjeździe wraz z rodziną do USA pracował w University of Southern California (1983-1989) oraz w California State University (1992-2012), skąd w 2012 roku odszedł na emeryturę. W Stanach Zjednoczonych wykładał wiele przedmiotów związanych z nauką o komputerach i informatyką, między innymi organizację masowych danych i data mining. Już po 2000 roku, jako profesor amerykański, był zatrudniony w prywatnej uczelni w Nowym Sączu, cieszącej się dobrą sławą i wysokim poziomem nauczania.

Lubił zwiedzać osobliwości przyrodnicze i architektoniczne kontynentu amerykańskiego. Aktywnie uczestniczył w życiu naukowym i kulturalnym Stanów Zjednoczonych.

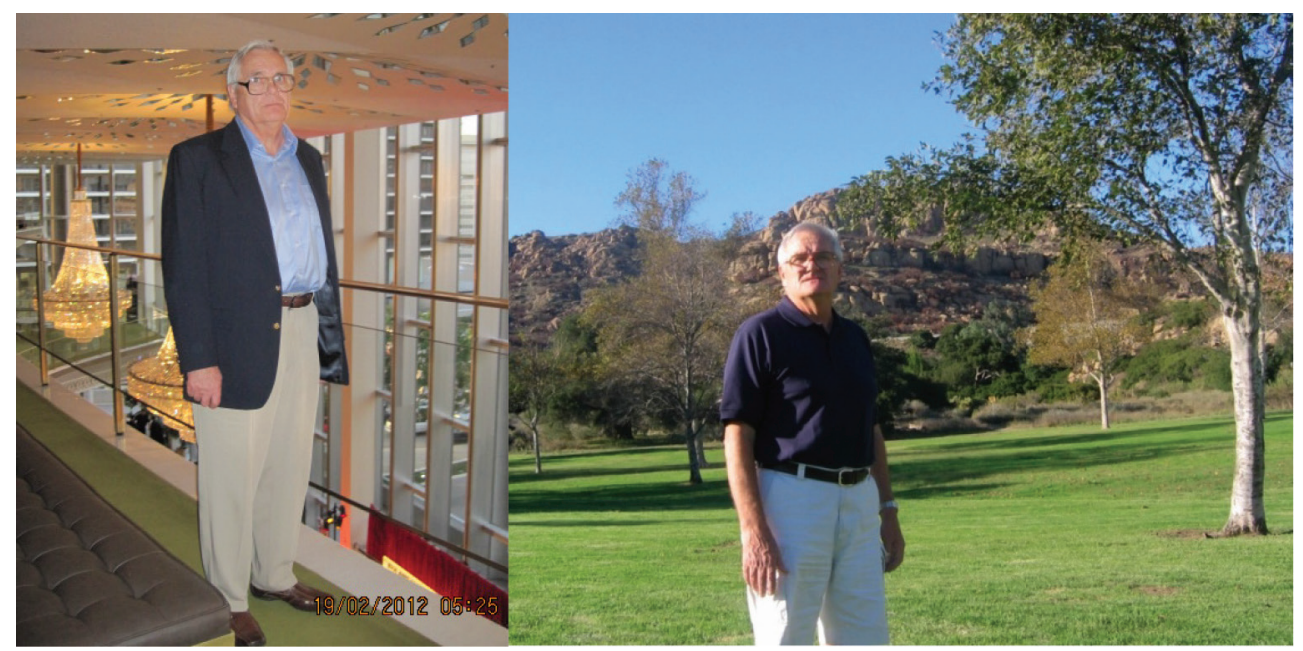

Ginter w operze w Los Angeles

G. Trybuś w Chatsworth Park, USA, 2005 rok

Żonie - Elżbiecie Trybuś -

dziękujemy za niektóre wykorzystane w opracowaniu informacje

\section{Literatura}

Bartosiewicz S., 2007, Ekonometria wrocławska, Wydawnictwo Akademii Ekonomicznej we Wrocławiu.

Cieślak M., Smoluk A., Szmigiel C., 2016, Profesor Ginter Antoni Trybuś, Portal (pismo Uniwersytetu Ekonomicznego we Wrocławiu), Portal 1(24). 


\section{Najważniejsze publikacje Gintera Trybusia}

Zmienna losowa dystansowa. Teoria i zastosowania, 1981, Akademia Ekonomiczna, Wrocław.

Maszyny cyfrowe i ich zastosowania (współautor), 1978, PWE, Warszawa (było kilka wydań pod zmienionym tytułem).

O aproksymacji rozkładów wielowymiarowych na podstawie małej próby (współautor), 1969, Prace Naukowe WSE we Wrocławiu.

Uwagi o multyplikacji próby wielowymiarowej, 1972, Prace Naukowe WSE we Wrocławiu, 32.

Algorytm wyznaczania wierzchołków wielokata wypukłego, 1972, Prace Naukowe WSE we Wrocławiu, 35.

Zastosowanie zmiennej losowej dystansowej do przybliżonego rozwiazania problemu komiwojażera, 1972, Prace Naukowe WSE we Wrocławiu, 35.

Generatory liczb pseudolosowych dla maszyny cyfrowej Odra 1003 (współautor), 1972, Prace Naukowe WSE we Wrocławiu, 35.

Statistical prediction by the method of harmonical weights, 1973, Zastosowania Matematyki, XIII, 4.

Calculating the measures of economic maturity, 1973, Zastosowania Matematyki, XIII, 4.

Programowanie komputera Odra-1204 - zadania i ćwiczenia (współautor), 1974, PWE, Warszawa.

On the distance random variable, 1973, Zastosowania Matematyki, XIV, 2.

Calculation of measures of stochastical dependence, 1973, Zastosowania Matematyki, XIII, 4.

Sprawozdanie z konferencji statystyków i ekonometryków Polski poludniowej w Karpaczu. Przegląd Statystyczny, 2/74.

Synchronizacja operacji w liniach montażowych (współautor), 1978, Prace Naukowe AE we Wrocławiu, $\mathrm{nr} 141$.

Enclosure of a point to the minimum spanning tree, 1976, Zastosowania Matematyki, XV, 1.

Heurystyczna metoda synchronizacji czasów operacji w liniach montażowych, 1978, Mechanik, 3.

O pewnym algorytmie wyznaczania ciagu dystansów dla n punktów, 1968, Prace Naukowe WSE we Wrocławiu, 12.

O pewnej iteracyjnej metodzie wyznaczania ciagu dystansów, 1968, Przegląd Statystyczny, 1.

Algorytm wyznaczania wierzchołków wielokąta wypukłego, 1972, Prace Naukowe WSE we Wrocławiu, 35.

Distribution of the k-th Ordered Distance Random Variable, 1985 (with E. Trybus), 1985, American Statistical Association, Proceedings of Statistical Computing Selection.

Application of the Distance Random Variable to the Minimum Spanning Tree Problem, 1986 (with E. Trybus), 1986, American Statistical Association, Proceedings of the Statistical Computing Section.

The Distance Random Variable and Its Applications, 1989, Communications in Statistics, vol. 18, no. 3 .

An Analysis of the Minimal Spanning Tree structure (co-author E. Trybus), 1992, Proceedings of the International Symposium on Computational Statistics COMPSTAT, Switzerland.

Statistical Data Bases and Relation Data Bases, 1993, Computer Science and Statistics, INTERFACE. Computer Technology in the Business Curriculum (with E. Trybus), 1996, Proceedings of the International Conference on University Education, Brno, Czech Republic.

International Benchmarking and Teaching Total Quality Management (with E. Trybus), 1998, Proceedings of $8^{\text {th }}$ Annual Conference, Center for Reasearch on East European Business (CREEB).

Total Quality Management in a Joint-Venture Company: A Case Study (with E. Trybus), 1999, Proceedings of the Portland International Conference on Management of Engineering and Technology, vol. 1, Book of Summaries, Portland. 


\section{Aneks 1}

List Elżbiety Trybuś z dnia 15 grudnia 2015 roku do Marii Cieślak

\section{Marysiu!}

Bardzo Ci dziękuję za list. Byłam bardzo zajęta po powrocie z Polski, bo wiadomo, jak dzieci gospodarzyły w domu, a Ania zajęta pracą i dziećmi, to pracy miałam sporo, by wrócić do normalnych warunków.

W ostatni czwartek listopada obchodzi się Święto Dziękczynienia i wtedy są praktycznie trzy dni wolne. Mój syn i synowa przyjechali w niedzielę przed tym świętem i odlecieli z powrotem do Chicago w czwartek rano, a ja pojechałam do San Diego, bo Ania, czyli druga nasza córka, pojechała tam z dziećmi i cały obiad był u Iwonki koleżanki, także lekarki pulmonologii.

Wróciłam w sobotę rano szczęśliwie i cało. Miałam niedawno taki niemal wypadek. Kiedy jechałam autostradą, samochód po lewej stronie stracił panowanie i przejechał tuż przede mną w poprzek, odbił sie od ściany po prawej stronie i jego przedni zderzak znowu przeleciał przed moim samochodem. Mogłam być dwa razy uderzona, ale cudem nie było nawet zadraśnięcia.

Niestety, to jeżdżenie w Stanach jest konieczne i trzeba uważać. Dzisiaj na drodze do opery Iwonka poczuła, że coś sie dzieje z samochodem, więc wezwałyśmy pomoc techniczną i już po operze, bo na ogół jedzie się o godzinę wcześniej, aby zdążyć. Cóż robić - miasto, które ma ponad 4 miliony mieszkańców, ma bardzo złą komunikację. Nawet do metra trzeba dojechać.

Sytuacja w Paryżu, a w tym tygodniu w Kalifornii w San Bernardino, gdzie zostało zabitych 14 osób, tłumaczy, w jakim stresie ludzie żyją, i nie wiadomo, dlaczego jest tyle nienawiści i walk na tle religijnym czy narodowościowym. W Waszyngtonie flaga opuszczona do połowy na znak żałoby. Jeszcze w ubiegłym tygodniu mówiliśmy, że będzie niebezpiecznie lecieć do Europy, a tutaj w sąsiedztwie $70 \mathrm{~km}$ to się stało. Mam już tego dosyć.

Właśnie, dziękuję, że pomimo upływu czasu, będzie można napisać kilka słów o Ginterze. Tak jak mówiłam już tutaj, nigdy nie narzekaliśmy na nasze warunki i pracę w Polsce. Nasz wyjazd był podyktowany przyszłością dzieci. Lepszych kolegów i atmosfery w pracy, jaką mieliśmy w Polsce, nie można sobie wyobrazić. Tego Ginterowi bardzo brakowało, bo zawsze był towarzyski i bardzo często rozmawiał z pracownikami z innych departamentów. Ponieważ geografię miał w jednym palcu, więc potrafił nawet powiedzieć, z jakiej części Indii jest student czy pracownik. $\mathrm{Z}$ każdym miał zawsze temat do rozmowy, jeżeli nie o polityce, to o sporcie czy innych ciekawych sprawach, o których nawet ludzie urodzeni w danym kraju nie wiedzieli. Czytał bardzo dużo; trochę jeździliśmy, ale mówił nieraz, że wszędzie nie 
musi być. Iwonka leciała co Chin, a ja potem z nią i jej koleżanką byłam w Izraelu prawie dwa tygodnie, a Ginter już nie dał się namówić na większe wyprawy.

Często studenci przynosili mu znaczki pocztowe ze swojego kraju. Filatelistykę zaczął bardzo wcześnie, bo jeszcze ze swoim dziadkiem, i nawet jak wyjechaliśmy do Stanów, to kolega wysyłał mu znaczki, które były zamawiane w Klubie Filatelistycznym w Polsce. Nie wiem, czy któryś z wnuków wykaże takie zainteresowania. Komputery i Internet zastępują im cały świat. Wystarczy nacisnąć klawisz i już ma się wszystkie wiadomości. Ginter bardzo lubił uczyć i studenci go również lubili, bo jakiś dowcip od czasu do czasu im wymyślił. Nie puszczał słabych studentów i oni oblewali egzaminy, co wiąże się tutaj z opłaceniem i powtarzaniem całego kursu. Mam taki wycinek z gazety z Uniwersytetu Południowej Kalifornii w Los Angeles, gdzie uczył 6 lat, w której miał wywiad i właśnie porównywał sposób uczenia w Polsce i w Stanach. [...]

Pozdrawiam

Elżbieta z Rodzina 


\section{Aneks 2}

\section{Information about the death of Professor Ginter Trybuś prepared overseas by his friends}

Ginter Trybus was born in Rybnik, Poland, on June 13, 1940 to Jan and Irena. He acquired his master and doctorate degrees from the University of Wroclaw, Poland. Ginter taught courses in Computer Science at Wroclaw University of Economics. He received numerous awards from the Ministry of Science and Higher Education for his scientific dissertations, co-authored textbooks in Computer Science, monograph papers, and series of articles published in international journals. He was fluent in five languages (Polish, Czech, German, Russian and English).

Ginter married his wife, Elzbieta Trybus (Elizabeth) in 1963, also a professor in statistics and operations management. In 1982 Ginter Trybus arrived in Los Angeles with his wife and three children. He taught at the University of Southern California (USC), UCLA and at the California State University in Northridge, in the Computer Science Department. Ginter retired in 2012 to enjoy spending time with his children and grandchildren.

He was a dedicated teacher and will be remembered for his sense of humor, character, compassion, and loyalty.

He is survived by his wife Elizabeth, daughters Iwona and Anna, son Krystian, his brother Erwin and sister Halina Rzok, and four grandchildren Alicja, Victor, Patrick and Oliver. Throughout his life Ginter remained a devoted Catholic and a man of great faith.

Ginter Trybus, Elizabeth's husband, passed away suddenly on Feb. 6, 2014.

$* * *$

The Rosary prayer will be on Wednesday, Feb 12 at 6:30 p.m. in the Mission Hills Catholic Mortuary, 11160 Stranwood Ave, Mission Hills, CA 91345.

The funeral Mass will be on Thursday, Feb 13 at noon in the Our Lady of the Bright Mount Church, 3424 West Adams Blvd., Los Angeles, CA 90018. 